\title{
“Toda Quebrada na Plástica” - Corporalidade e construção de gênero entre travestis paulistas
}

Larissa Pelúcio

UFSCar
"Não há inocência nos órgãos no imaginário ocidental, a parte vale pelo todo físico e moral"

(Le Breton).

Niky é "belíssima". O que a faz belíssima, acima de tudo, é ser "toda quebrada na plástica". Tornou-se arredondada, suavizou tudo o que nela era anguloso, duro e reto: características atribuídas ao corpo masculino. Fez nariz e testa; refez seios e abdômen, cultiva cabelos longos e naturais, aos quais dedica muitos cuidados; tem a pele bronzeada, onde as marcas do biquíni delineiam contornos. No rosto, nem um vestígio de pêlos pode ser detectado. Niky "se cuida".

Entre as travestis ${ }^{1}$ ser belíssima é uma classificação estético-moral que aponta para um conjunto de cuidados que estas dedicam ao corpo e, assim, à construção da pessoa ${ }^{2}$. É este "se cuidar" que atesta a determinação da travesti em se transformar e assim adequar seu corpo "de homem"3 aos seus desejos e práticas sexuais, construindo para si o que Butler (2002) chama de "gêneros inteligíveis". De acordo com a autora, "gêneros 'inteligíveis' são aqueles que, em certo sentido, instituem e mantêm relações de coerência e continuidade entre sexo, gênero, prática sexual e desejo". Essa inteligibilidade dada pela norma heterossexual é a mesma que as torna seres "abjetos". Isto é, aqueles que são alocados pelo discurso hegemônico nas "zonas invisíveis e inabitáveis" onde, segundo Butler, estão os seres que não são apropriadamente generificados. Os que, vivendo fora do imperativo heterossexual, servem para balizar as fronteiras da normalidade, sendo fruto, portanto, desse discurso normatizador que institui a heterossexualidade como natural. A normalidade se circunscreve a partir da fixação desses territórios onde vivem os corpos que não importam, uma vez que o abjeto é também o não humano (Butler 2002).

Mas o que é ser travesti? As travestis são pessoas que se entendem como Campos 6(1-2): 97-112, 2005. homens que gostam de se relacionar sexual e afetivamente com outros homens. Para 
tanto procuram inserir em seus corpos símbolos do que é socialmente tido como próprio do feminino. Porém, não desejam extirpar sua genitália, com a qual, geralmente, convivem sem grandes conflitos. Mas não basta se vestir de mulher para ser travesti. Para Claudinha Delavatti, travesti já falecida, "travesti que não toma hormônio não é travesti, pensa que é carnaval e sai fantasiado de mulher" (apud Lopes 1995:225). Hélio Silva, em sua etnografia sobre as travestis da Lapa (Rio de Janeiro), cita uma delas que diz que, além dos hormônios, é preciso que se façam aplicações de silicone a fim de dar forma ao corpo (Silva 1993:117). Além dessas intervenções no corpo e da apreensão de uma série de técnicas corporais que as distanciam dos padrões masculinos, as travestis buscam se conduzir segundo prescrições de comportamentos socialmente sancionados como femininos (Pelúcio 2004: 26 e 127 ).

Não se pode tornar travesti sem que se entre em uma rede de relações já estabelecida. Pois é ali que elas aprendem a se maquiar e a se depilar com eficiência; a andar e gesticular como mulher; a mudar a voz e o nome; a tomar hormônios; e onde e com quem colocar silicone. Só assim pode-se iniciar a construção da pessoa travesti.

\section{NO CORPO}

"Ser travesti" é um processo, nunca se encerra. Construir um corpo e cuidar deste é uma das maiores preocupações das travestis. Estão sempre buscando o que elas chamam de "perfeição", o que significa "passar por mulher". Não por qualquer mulher, mas por uma bonita e desejável. Isto é: geralmente, a branca e burguesa. Em busca dessa imagem afinam seus traços, bronzeiam seus corpos, adornam-se com roupas que remetem a mulheres glamourosas, escolhem nomes comuns a atrizes e musas hollywoodianas ou a cantoras pop. Desta forma não subvertem a norma, mas a ela se submetem.

Se "ser travesti" é algo continuado e sem fim, este processo tem um começo, que se divide em algumas etapas. A primeira delas (1) é quando ainda se é "gayzinho" (classificação êmica), ou seja, já se assumiu a orientação sexual para familiares e para "a sociedade" (como elas dizem, ou seja, para um conjunto mais abrangente de pessoas), mas ainda não se vestem com roupas femininas ou ingerem hormônios. Segue-se, então, (2) a fase do "montarse", o que significa, no vocabulário próprio do universo homossexual masculino, vestir-se com roupas femininas, maquiar-se de forma a esconder a marca da barba, ressaltar as maçãs do rosto, evidenciar cílios e pálpebras, além da boca. Vestir-se com roupas femininas ainda é, nessa etapa, algo ocasional, de tom furtivo, restrito a momentos de lazer ou noturnos. O terceiro momento é o da (3) "transformação". Esta é uma fase mais nuançada, pois tanto pode envolver apenas depilação dos pêlos do corpo e vestir-se cada vez mais freqüentemente como mulher, como pode indicar o momento inicial de ingestão de hormônios, quando estes ainda não produziram efeitos perceptíveis; e finalmente, (4) a quarta etapa, quando já se é travesti. Pois além do consumo de hormônios, vestem-se todo o tempo com roupas femininas (sobretudo roupas íntimas, pois se pode estar de shorts, sem camisa, mas de calcinha) e, no mínimo, já se planeja injetar silicone nos quadris e nádegas. 
A transformação seria então esse processo de feminilização que se inicia com extração de pêlos da barba, pernas e braços; afina-se a sobrancelha, deixa-se o cabelo crescer e passa-se a usar maquiagem e roupas consideradas femininas nas atividades fora do mundo da casa. A seguir, começa a ingestão de hormônios femininos (pílulas e injeções anticoncepcionais e/ou de reposição hormonal), passando por aplicações de silicone líquido nos quadris e, posteriormente, nos seios, até se chegar (e nem todas podem fazê-lo por absoluta falta de dinheiro) a intervenções cirúrgicas mais radicais como operação plástica do nariz, eliminação do pomo-de-adão, redução da testa, preenchimento das maçãs do rosto e colocação de próteses de silicone.

São poucas as que conseguem essa transformação tão apurada. Normalmente as que a alcançam são as "tops" e/ou "européias"4. As primeiras são travestis que fazem filmes de sexo explícito e ensaios fotográficos de igual teor. São tidas pelas demais como "belíssimas". Muitas delas têm acesso freqüente à internet, onde mantêm blogs e fotoblogs ${ }^{5}$. O uso contumaz das plataformas disponibilizadas pela internet as faz mais conhecidas e prestigiadas, o que permite que cobrem até $\mathrm{R} \$ 150$ por uma hora/uma hora e meia de programa completo (sexo com penetração).

Gladys Adriane, travesti "top", acredita que uma verdadeira "top" deve falar pelo menos dois idiomas. Ela fala inglês e espanhol, além do português, e espera voltar de sua temporada na Itália versada no italiano também.

As "tops" têm que falar outros idiomas, mas não devem falar o "bajubá" ou "pajubá" (ambos os termos são usados), gíria própria das travestis que tem sua origem no ioruba-nagô. Lembro-me de Juliana Nogueira, uma "top", comentando que na casa onde morava havia uma caixinha para depositar a multa de $\mathbf{R} 1$ por se falar "bajubá".

Outro requisito citado por Gladys, bem como por Victória Ribeiro, também reconhecida como "top", diz respeito aos cuidados estéticos, o que inclui o uso de produtos de marcas caras: "das pontas das unhas dos pés até o último fio de cabelo deve ser intacto e o mais perfeito possíveis... pele então...", declara Gladys em conversa via MSN. Isso demanda muitos gastos. Victória, que usa produtos para cabelos da marca Kèrastase, comprava xampus que custavam entre $\mathrm{R} \$ 40$ e 60. “Praticamente $70 \%$ dos meus ganhos é em minha imagem... agora não, eu tracei outras metas e quando você vai ficando com a imagem que desejou passa a gastar um pouco menos...", explica-me Gladys.

Ser uma "top" ou "européia" pode significar por vezes a mesma coisa. Mas nem toda "européia" é "top", assim como nem toda "top" é "européia". Pois para ser "européia", como o título indica, é preciso ter vivido uma temporada atuando como prostituta lá fora. Desde os anos de 1980 as travestis descobriram a prostituição na Europa e passaram a atuar por lá.

Quando Paris era o sonho de ascensão das travestis, imperava também o estilo "travecão": ancas fartas, muito seio, boca carnuda, coxas volumosas. O exagero é a marca desse "corpo Paris", e é justamente o excesso que remete à imagem masculina. Como me explica Fabyanna Toledo ${ }^{6}$, que no exato momento vive sua primeira temporada na Europa: um "travecão" "nunca passará por mulher".

Como todo o conjunto de padrões estéticos das travestis, este também está ligado a valores morais próprios do grupo. Por exemplo, pode-se ser "gayzinho", mas só é tolerado que se tenha um visual andrógino e indefinido 
na fase inicial da transformação. Depois disso a pessoa passa a ser vista como desleixada ou mesmo covarde, por não ter coragem de ir a fundo na transformação. $\mathrm{O}$ "travecão" está ligado ao exagero, ao masculino e, portanto, ao insucesso ou ao ultrapassado. Valoriza-se atualmente o estilo "menininha", isto é, mais natural: curvas mais enxutas, seios menos exagerados, roupas mais ao gosto das adolescentes que aparecem em programas televisivos como Malhação (soap opera veiculada pela Rede Globo de televisão no horário da tarde). Fazendo a "linha patricinha". Fazer a linha significa "agir como se fosse".

Como as adolescentes e jovens heterossexuais, as travestis também se deixam seduzir pelos apelos da moda, por padrões estéticos rigidamente estabelecidos pela mídia, e assim muitas delas buscam legitimidade reproduzindo esses valores estéticos.

Os "travecões" denunciam o insucesso na transformação e a idade, enquanto as "ninfetinhas" e/ou "patricinhas" são o reverso da moeda. São jovens - valor cultivado no grupo, pois as coloca em melhor posição no mercado sexual - e podem ter acesso a toda uma tecnologia estética que não estava disponível até muito recentemente - o que as torna "mais bonitas" e mais bem-sucedidas em seu processo de transformação. Porém as mais velhas, "travecões" ou não, consideram-nas "abusadas", quer dizer, que são desrespeitosas e arrogantes. $\mathrm{O}$ que aborrece as mais velhas é que as jovens não admitem sua inexperiência e esnobam aquelas que "abriram as portas para elas".

Como se vê, a intervenção na carne é também uma alteração moral. Por isso Jennifer, travesti de 22 anos, tem certeza que mudará seu jeito de ser quando colocar a sua prótese de seios. "Mudar como?", quero saber. “Não sei, mas eu vou ficar diferente, closeira7, não sei. Diferente de como eu sou agora".

\section{NOS NERVOS}

Mesmo sem suas sonhadas próteses, que ela deve colocar com um cirurgião plástico famoso entre as travestis paulistas, Jennifer sente-se alterada quando aumenta a ingestão de hormônios femininos. Isso porque os hormônios femininos que ingere a deixam "nervosa". Essa perturbação se manifesta pela irritabilidade, pela propensão maior a "estourar", a não ter controle sobre seus sentimentos e reações.

Como a literatura antropológica sobre o "nervoso" indica (Duarte 1988, Cardoso 1999, Levigard 2001), este é "percebido como uma categoria culturalmente interpretável" (Levigard 2001: 16), integrando aspectos físicos, morais, sociais e mesmo espirituais. Assim, para as travestis, ser ou estar "nervosa" tem relação com uma situação físico-moral específica que as associa a elementos socialmente sancionados como femininos. É por meio da ingestão sistemática de remédios contraceptivos ou para reposição hormonal de mulheres na menopausa que as travestis iniciam seu processo de transformação. Como relata Gabrielle, travesti ouvida por Benedetti: 
“Eu acho que o hormônio na vida de uma travesti é a feminilidade toda, tudo tá ligado ao hormônio. Inclusive, tem amigas minhas que quando vão à farmácia comprar hormônios elas costumam colocar assim, ó: '- Eu vou comprar beleza.'; porque o hormônio é realmente a beleza na vida de uma travesti. Ele ajuda na pele, que fica mais macia (...), inibiu o crescimento de pêlos, desenvolveu a glândula mamária, entendeu, arredondou formas, e até a expressão do olhar de quem tomou hormônio é diferente (...). A gente fica mais feminina prá falar, prá sentar, e tudo isso é efeito do hormônio no teu organismo" (Benedetti 2000:66).

"O hormônio é como o alimento do corpo", explica-me Juliana, travesti de 20 e poucos anos, já bastante transformada pelas plásticas, bem como pelo uso de hormônios.

Analisando os dois depoimentos vê-se que o hormônio se confunde com qualidades atribuídas simbólica e fisiologicamente ao sangue. Ele dá vida, mas não qualquer vida, mas a de travesti, como também propõe Benedetti (2000). Entra no sangue e, assim, circula pelo corpo, conferindo à travesti os atributos desejados da feminilidade, assim como os indesejados. Hormônios engordam, declaram muitas. Abrem o apetite e reduzem o desejo sexual.

Verônica, bombadeira ${ }^{8}$, surpreende-se quando digo a ela que já ouvi falar que o hormônio "suja o sangue". "Ao contrário", afirma, "ele limpa. Pelo menos pra mim, que tomo hormônio, limpa. Me ajuda a limpar o rosto, as espinhas começam a sair. Acho que pra todas"9. Assim, o hormônio circulando pelo sangue limpa a travesti daquilo que é masculino: pêlos, pele grossa, traços angulosos. Atribui a elas também qualidades morais vistas como próprias da mulher: sensibilidade, delicadeza e até mesmo dedicação ao lar. Bruna, travesti de 24 anos, é quem fala sobre os efeitos do Gestadinona combinado com Perlutam. Seu cheiro muda, sua relação com a casa também. Fica muito exigente com a organização doméstica, não suporta ver nada fora do lugar. Pega gosto por lavar louças e roupas, de tal forma que suas roupas brancas ficam numa alvura sem igual. Adora passar também, função na qual se esmera, pois não suporta, quando está sob efeito desse hormônio, nenhum "amarrotadinho", tanto que dedica longos minutos na arrumação da cama, pois precisa ver os lençóis bem esticados, até que nenhuma "dobrinha" apareça. Essa obsessão a deixa nervosa, avalia ela. O desinteresse por sexo a leva a não ter orgasmo e, portanto, ejaculação, o que agrava o estado de nervos.

Já Victória Ribeiro declara o contrário, para ela a ereção se torna difícil se não está tomando hormônios, pois sem seus trejeitos femininos afirma não conseguir se sentir bem, isso inclui ter prazer com seu corpo, o que incide na sua sexualidade. "Eu sou viciada em hormônios", confessa. Quando está bem hormonizada fica com "cabeça" de mulher, o que significa não querer saber de coisas masculinas como "competitividade, agressividade e promiscuidade" e a leva a procurar menos sexo, fazendo só o que a sua profissão exige.

Muitas travestis já me relataram a relação entre ter um pênis e a necessidade de ejacular com freqüência. Mais do que isso, elas precisam "gozar" para não ficarem "nervosas". O fluido masculino não pode ficar retido no corpo: não seria "natural". Porém, se gozam muito deixam o hormônio feminino sair. É o que me diz Sasha, travesti muito bem cotada no mercado sexual paulistano, ao me mostrar algumas fotos do seu último ensaio fotográfico:

- "Mulher, olha como os meus peitos estavam grandes!"

- "E por que não estão mais, você parou de tomar hormônios?" - pergunto.

- “Não, mulher, tenho gozado demais, aí já viu, né, vai tudo embora." 
Outras já me disseram que isso é "bobagem", "crendices", o que não se pode fazer mesmo é tomar bebida alcoólica, só cerveja, um pouco. Mas, segundo me explica Bárbara, que também é atriz de filmes pornôs e modelo de ensaios fotográficos, para mulheres não há problema, podem tomar os hormônios, isto é, pílulas anticoncepcionais e ingerir álcool que nada acontecerá, mas com as travestis o efeito é sensível: perdem os resultados do tratamento.

As divergências de opinião sobre os usos e efeitos dos hormônios femininos encontram uma convergência na idéia de "nervoso". A travesti hormonizada fica nervosa, sem gosto para o sexo, que, como se viu, aumenta o nervoso, pois não se goza.

No seu já clássico Da Vida Nervosa nas Classes Trabalhadoras Urbanas, Luiz Fernando Duarte identifica a categoria do "nervoso" à mulher/feminino:

“... é mais nervosa, nesse sentido, por ter uma sensibilidade que se antepõe logicamente à força, embora pressuponha a idéia de uma resistência. (...) Mais nervosa, ainda, por ser justamente mais 'moral', mais próxima ou consentânea com a reprodução 'moral' da casa" (Duarte 1986: 180).

Quando "hormonizadas", as travestis passam a ter no "sangue" o feminino.

\section{NA CARNE}

Se o hormônio é a feminilidade, a beleza e o nervoso, que confirma os resultados da feminilização, o silicone é "a dor da beleza". O corpo feito, todo "quebrado na plástica" é o sonho da maioria. Mas nem sempre as intervenções podem ser conseguidas em clínicas de cirurgia plástica filiadas ao sistema da medicina oficial. Então, procura-se o caminho tradicional, aquele que vem sendo usado há pelo menos 30 anos pelas travestis: a bombadeira. É Paulette, travesti com mais de 50 anos e atualmente agente de prevenção do Tudo de Bom! ${ }^{10}$, quem conta:

Pesquisadora - “E aí, quando apareceu o silicone, como é que foi? Teve uma procura muito grande?"

Paulette - "Ah, teve! Ah, teve, porque aí as bichas ficaram enlouquecidas. Porque ninguém mais queria tomar hormônio. Aí todo mundo queria bombar peito, bombar bunda. E também foi a época das próteses. Todo mundo queria pôr prótese."

Desde então, são as bombadeiras que injetam silicone líquido no corpo das travestis. As bombadeiras são na sua imensa maioria travestis também. Cabe a elas "fazer o corpo" através da inoculação desse liquido denso e viscoso, usado como óleo para lubrificar máquinas, no corpo das suas clientes. O processo é dolorido, demorado e arriscado. 
Todas as travestis parecem saber que se bombar é perigoso. Mas a maioria não abre mão dessa técnica de transformação do corpo. Em pesquisa realizada pela Unidas, associação formada por travestis de Aracaju (SE), constatou-se que mesmo $68 \%$ das 22 travestis entrevistadas sabendo dos riscos do silicone industrial, e $92 \%$ delas conhecendo pessoas que tiveram problemas com o uso do mesmo, $80 \%$ delas fariam aplicações do produto ${ }^{11}$. Essa realidade se verifica também entre os grupos de travestis que fazem parte desta pesquisa (travestis da capital e do interior de São Paulo).

O desejo de "ter um corpo" se sobrepõe aos "riscos" implicados nessa construção, como observou também Sabino (2004) em sua pesquisa entre fisiculturistas cariocas. Ele adverte que antes que julguemos esses procedimentos em busca de um corpo específico como ignorância ou irracionalidade, devemos

“focalizar o aspecto social que confere significado a tal uso. Este, freqüentemente, está imerso em sistemas simbólicos com lógica própria. Em se tratando do sistema simbólico inerente aos grupos sociais das academias, a dor e o sacrifício aparecem como um preço a ser inevitavelmente pago pela conquista de uma vitória presumível na construção de uma identidade inerente à aceitação em um grupo restrito (Sabino 2004:169).

Bombar-se é entrar definitivamente no mundo das travestis e com ele compactuar. Por isso, algumas travestis "tops" asseguram que não têm nem nunca terão esse "lixo" no corpo. Criam, dessa forma, uma clara distinção entre elas e as "outras": pobres, "feias", "viados de peito".

Houve um dia em que cheguei à casa de Cláudia, à época cafetina e bombadeira em São Carlos, e encontrei Sandra, uma das inquilinas da casa, andando nos calcanhares, devagar. Naquela semana mesmo Cláudia havia "bombado" seus quadris. As demais travestis da casa recomendavam em tom maternal que Sandra fosse se deitar.

É preciso ficar de bruços e quieta, para evitar que o silicone "escorra". Na verdade ela se levantou porque um dos furos estava vazando e ela não sabia o que fazer. Recomendou-se esparadrapo e repouso. Nesses 15 dias, aproximadamente, de recuperação, ela não deve ingerir comidas "quentes", chocolate, coisas apimentadas, bebidas alcoólicas, para não ter complicações ${ }^{12}$. Dentro das práticas de cuidados das travestis categorias próprias do universo popular estão presentes. É a esse conjunto de saberes que recorrem nesses momentos. Algumas terapias próprias da medicina oficial são incorporadas a estes cuidados, como o uso de anestésicos, ingestão de antiinflamatórios e antibióticos, mas, na maioria das vezes, são ministrados pela bombadeira ou por uma travesti mais experiente. Pode-se dizer que elas guardam uma certa "autonomia terapêutica" em relação às recomendações vindas da medicina oficial.

Jennifer já teve problemas com o uso de silicone e, ainda assim, colocou mais. Agora diz que parou. Foi ela quem me informou que as agulhas utilizadas na aplicação são de uso veterinário, precisam ser grossas para que o líquido viscoso passe. Verônica, bombadeira que tem se mostrado muito talentosa, ensina-me que na hora da aplicação a agulha deve penetrar até a terceira camada da pele, evitando que se pegue alguma veia, como já aconteceu com Jennifer ao bombar-se. 
“Precisa ter muito cuidado na hora de injetar. Não pode pegar a corrente sangüínea. A primeira vez que eu fui injetar, a mulher pegou a corrente sangüínea. A gente vê logo que pegou porque a seringa enche de sangue. Aí ela pôs superbonder [marca de cola] e parou. Se pegar a corrente sangüínea já era, vai descer mesmo. Pra mim desce tudo pra esse pé [direito] ${ }^{13}$.

Para que isso não aconteça as bombadeiras fazem amarrações cuidadosas em pontos específicos. Se vão bombar quadril e bunda é preciso amarrar o corpo com faixas de pano na cintura e abaixo dos joelhos (ainda que algumas prefiram não amarrar nesse local). Depois, recomenda-se que a travesti fique uma semana com calcinha para desenhar melhor o corpo, levantando-se apenas para se banhar e permanecendo de bruços. Se bombar os seios, os cuidados devem ser ainda maiores. Sobretudo para a bombadeira, pois a proximidade com o coração e pulmão faz como que um erro nessa região seja fatal. Os seios exigem amarrações complexas e cuidados posteriores que pedem determinação e obediência. Por vezes é preciso que se passe semanas (de 2 a 3) com um objeto cilíndrico entre os monturos dos seios. Usam-se pedaços de cabo de vassoura ou de canos de PVC (usados para fins hidráulicos).

Jocasta, também bombadeira, diz que o mais difícil é fazer com que a paciente siga as recomendações de repouso. "O corpo fica pronto na hora, e aí muitas já querem sair pra mostrar, naquele deslumbre", conta-me. Verônica faz o mesmo tipo de observação: sem que a "bicha" siga as recomendações feitas pela bombadeira o sucesso do trabalho fica comprometido. Além do repouso, as bombadeiras pedem que não se use salto por pelo menos um mês, no caso de bombar quadril e bunda; que se durma sentada, quando se trata dos seios e do rosto. Além disso é essencial observar a dieta alimentar. Nada de alimentos quentes ou reimosos.

Miriam me dá outros detalhes sobre os cuidados em relação à dieta:

“A pessoa que coloca silicone, ela não pode comer carne de porco. Carne de porco, ovo, dependendo do peixe, não pode comer. Uma coisa muito difícil assim de colocar silicone, porque dá muito furunco [sic]. Geralmente a pessoa que come, dá muito furunco [sic] na pessoa, né?"14.

Antes de ouvir esse depoimento, já havia escutado Jeniffer dizer que silicone "suja o sangue". É quente, por isso faz sair impurezas na pele. Esse tipo de observação leva-me a classificar o silicone como um elemento "quente", por isso mesmo forte. Como tal, o seu uso não deve ser associado a alimentos também considerados fortes e quentes. Esse tipo de classificação de alimentos em associação com partes do corpo e elementos da natureza é bastante recorrente entre classes populares, que se valem dessa homologia compondo um modelo explicativo para moléstias, suas terapias e profilaxias ${ }^{15}$.

O desejo de se ver cada vez mais feminina, isto é, "bela", se sobrepõe aos receios em relação ao uso do silicone, como já discutido, pois se impõe como valor moral entre as travestis o "cuidar-se", que implica a busca permanente por padrões estéticos e comportamentais atribuídos à mulher. 
Cuidar-se inclui ainda uma série de práticas empreendidas diariamente (ou várias vezes por semana) pelas travestis. Estas vão dos cuidados com pêlos e cabelo a lavagens intestinais. Iniciemos com os primeiros.

Os pêlos e cabelos:

- "fazer o chuchu" (tirar a barba), o que pode ser feito com tratamentos estéticos em clínicas especializadas (/aser, eletrólise) ou mesmo com lâmina - prática malvista, pois remete a uma performance corporal masculina, além de denotar preguiça e falta de determinação;

- pinçar pêlos do rosto, desenhar sobrancelhas, alourar pêlos do corpo;

- escovar, hidratar, tingir, alisar, trançar, aplicar fios sintéticos nos cabelos;

- colocar, manter e valorizar a peruca ou aplique. Esse primeiro acessório é desvalorizado entre as travestis, pois o cabelo natural atesta o tempo que já se está em transformação, apontando também para um maior sucesso nesse processo.

Cuidados e técnicas de valorização do corpo:

- bronzear-se, seja naturalmente, expondo-se ao sol, ou em máquinas, para que a marca do biquíni, aspecto estético extremamente valorizado entre elas, fique bastante evidente. O bronzeado remete à imagem idealizada da mulher brasileira, principalmente a carioca: sensual, tostada pelo sol que bate em praias prestigiadas;

- pintar as unhas; mantê-las longas e bem cuidadas é sinal de status, bem como do valor moral do "cuidar-se", simbolizando a feminilidade ;

- maquiar-se, principalmente com bases que cubram possíveis asperezas da pele, em particular na região da barba. Valorizar o olhar com sombras e lápis;

- providenciar, manter e colocar enchimentos, principalmente para fazer os seios, método que a maioria pretende temporário;

- escolher roupas que evidenciem suas formas femininas ou que ajudem a "dar o truque", isto é, favorecer sua imagem. Para as que se prostituem, esse é um processo que requer muita atenção, pois as roupas devem mostrar atributos físicos. Aprende-se com o grupo esse processo de valorização de nádegas, quadris e seios, assim como a se mover dentro dessas roupas, sejam saias justas, tops minúsculos ou calças leggings muito agarradas ao corpo.

É aqui que entra a primeira técnica apreendida pelas travestis, muitas vezes sozinhas, na descoberta da sexualidade e de seus corpos: "aquendar a neca", o que significa esconder o pênis. A "neca" é cuidadosamente colocada entre as pernas, pressionando o saco escrotal e, dependendo do "dote"16 de cada uma, presa entre as nádegas; faz-se assim "a buceta", como elas gostam de brincar. Com a experiência e a prática, as que se prostituem aprendem a fazer isso na rua, ao sair de um programa. Abre-se as pernas, agacha-se um pouco curvando-se o corpo levemente para frente, ajeita-se a "neca" com as mãos e, por fim, sobe-se a calcinha, fazendo, então os ajustes finais.

Importante também, principalmente para quem faz programas, é fazer a lavagem anal, o que evita que se "passe cheque", isto é, suje com fezes o pênis do parceiro. Essa técnica pode variar de um asseio mais profundo, envolvendo a introdução da mangueirinha do chuveiro no ânus ou mesmo uma lavagem feita com produtos como 
Fleet-enema, encontrado em farmácias. Essas informações são passadas na convivência umas com as outras e atualmente nos diversos sites e blogs (ver nota 5) de travestis na internet. Drikka, travesti que mantém um blog próprio, ensina também aos clientes como proceder:

“Antes de você fazer sexo anal, vá ao banheiro e defeque ou tente ao máximo. Após isso, pegue a mangueirinha do chuveiro e encha de água e solte no vaso sanitário várias vezes, até você sentir que não tem mais nada pra sair. Tenha o cuidado de tirar toda a água, porque se ficar água internamente, também será chato!" (http://bone cadrikka.blig.ig.com.br/2003_10.html).

Os sapatos também compõem um item importante. Travesti gosta de salto, afirmam muitas. Mas é preciso saber andar sobre eles de maneira elegante e segura. Daí a expressão "no salto", que denota firmeza, desembaraço e elegância para lidar com situações delicadas. Andar no salto, literal ou metaforicamente, pede aprendizado, experiência. Ambos adquiridos num processo que mescla rupturas com a casa, com a família e proximidade com outras travestis. Esse momento ritual, em que se deixa de ser "gayzinho" para iniciar-se no mundo travesti, é marcado por medo, dor, incertezas, assim como pelo deslumbramento. Colocar o primeiro salto, a primeira peruca, aquela saia, é um desafio cercado de excitação. Mas não se compara à decisão de começar a ingerir hormônios, o que às vezes fazem com voracidade, consumindo até uma cartela de contraceptivos por dia. Ou o momento em que "se deitam" para a primeira aplicação de silicone industrial, materializando nas camadas de silicone a pessoa travesti. Como observa Le Breton, as alterações no corpo são também alterações morais (2003: 64).

\section{NA PELE}

É também Le Breton quem faz uma discussão instigante sobre literatura, ciência e corporalidade. Inicia seu texto com o clássico Frankenstein, de Mary Shelley, por considerá-lo a primeira obra literária a ressaltar com “inquietação a questão dos limites do homem e do uso do corpo humano como um material biológico disponível" (Le Breton 2004:52). O autor chama a atenção para outros mitos do gênero que são criados na ficção literária e readaptados, sobretudo, pelo cinema. Esse interesse popular pelo corpo transformado, recriado, moldado, montado, Le Breton atribui à condição essencialmente corporal do ser humano nas culturas ocidentais. Um corpo que delimita fronteira, individualiza e materializa preceitos morais e, eu diria também, "verdades" políticas, porque intrinsecamente ligadas a estruturas de poder como o Estado, a mídia, as religiões, a ciência, com destaque para a medicina, como tão bem discutiu Focault (1972 e 2003).

Na sua reflexão, Le Breton nos leva até a I/ha do Doutor Moreau (ficção de H.G Wells), com suas fantásticas e assustadoras criaturas inclassificáveis, pois mescladas e inomináveis. Fala-nos de sua ambigüidade como algo repulsivo e apavorante, mas esquece de dizer o que está evidenciado pelo sucesso de todas essas obras: o fascínio que essas criaturas provocam no imaginário ocidental. 
O corpo-valor ${ }^{17}$, quando violado, manipulado, rompe as fronteiras simbólicas, desnaturaliza, revela que esse corpo é histórico e cultural, muito mais do que natural. Le Breton conclui então que:

"Aquele que aspira à humanidade de sua condição sem oferecer a ela as aparências comuns, por causa de suas mutilações ou de suas deformidades, está destinado a uma existência diferenciada, sob o fogo dos olhares dos passantes ou das testemunhas de sua diferença. No imaginário, a alteração do corpo remete a uma alteração moral do homem" (Le Breton 2004: 64).

É justamente essa alteração moral que as travestis perseguem, na busca de adequar seus desejos a um gênero e, portanto, a um corpo. Diferentemente dos monstros da llha do Doutor Moreau ou de Frankenstein, elas não são construídas, mas constroem-se. Articulam essa construção a partir de referências heteronormativas, sujeitas que estão a padrões estéticos e a princípios morais afinados com o que o senso comum considera normal, belo e desejável. Não são aberrações incompreensíveis e sem identidade, mas seres tão construídos quanto qualquer um de nós, que cotidianamente marcamos em nossos corpos um gênero, um pertencimento de classe, uma identidade étnica.

Como as cultuadas top models - com suas dietas restritivas, ginásticas modeladoras e plásticas incontáveis a fim de conformar padrões quase inatingíveis em corpos inteligíveis - as travestis se valem de técnicas próprias, ou por elas apropriadas, da medicina e cosmética oficiais, a fim de alcançar um corpo desejado e desejável.

Se os normatizados fisiculturistas materializam em seus músculos forjados a ferro e boa dose de anabolizantes um masculino exacerbado, as travestis o fazem para fixar em seus corpos, de curvas e carnes arredondadas, um hiperfeminino. Corpos que longe de serem incompreensíveis, como somos levados a crer, são perfeitamente alocáveis em nossa ordem simbólica. $\mathrm{O}$ impedimento para que tal ocorra de fato está dado na questão fulcral que cerca as travestis: a relação obrigatória, dada como natural, entre sexo biológico e um gênero.

Ao romperem com a cadeia heteronormativa de gêneros inteligíveis, as travestis são alocadas para além das fronteiras da normalidade. Tornam-se assim corpos "abjetos", mas não inclassificáveis como os seres da ficção tratados por Le Breton. Ao intervirem no corpo preservando o membro que é tomado com um todo definidor - pênis-homem-masculino -, as travestis perturbam a ordem classificatória sem, contudo, subvertê-la de fato. Pois o que buscam é conformar esse corpo a uma ordem moral que pede que sexo, gênero, práticas e desejos se coadunem. O paradoxo se instaura aí, pois manterão em seus corpos, ainda que de certa forma normatizados, o elemento-síntese desestabilizador: o pênis.

Na busca infindável por um "corpo perfeito" as travestis acionam inúmeras técnicas de intervenção corporal. Estas vão de transformações epidérmicas a profundas intervenções, "quebrando na plástica" aquilo que em seus corpos possa remeter ao masculino. Ali manterão apenas o pênis, ou melhor, "a neca", um pênis precedido pelo artigo feminino. 
Para levar a cabo a construção desse corpo e desse gênero, as travestis desenvolvem todo um jogo de cintura para lidar com as constantes situações de ameaça a que estão submetidos os "abjetos". Procuram manterse "no salto", ainda que sejam muitos os tropeços para os que enfrentam as fronteiras de gênero insistentemente reafirmadas.

Para viverem no corpo, na carne, nos nervos e na pele essa transformação não legitimada é preciso "ter peito", ensinam-me as travestis. O que significa agir com a coragem que atribuem ao masculino, sem abrir mão da delicadeza que julgam própria do feminino. 
1 Uso o artigo feminino para me referir às travestis não só por uma posição política, mas também para estar mais de acordo com a forma como elas se tratam entre si. Ainda que não haja consenso sobre qual o gênero da palavra travesti, entre elas o uso dos artigos, pronomes e substantivos para se auto-referirem ou para tratarem aquelas que lhes são próximas é sempre no feminino.

2 Conceito usado aqui no sentido maussiano/dumontiano, o que significa considerar que a pessoa se constitui a partir de um sistema moral e de valores próprio de cada sociedade e/ou do grupo a que pertence. Desta forma, as culturas investem diretamente sobre os corpos, como bem ilustrado no estudo de Viveiros de Castro (1979), articulando os planos físico, psíquico e social que, assim imbricados, permitem que se considere os planos simbólico e empírico como esferas articuladas, capazes de orientar todo um conjunto de práticas estruturadoras da experiência humana.

3 Partindo de várias histórias de vida a mim relatadas, bem como da literatura sobre o tema (Silva 1993, Oliveira 1994, Silva e Florentino 1996, M. Oliveira 1997, Denizart 1997, Kulick 1998, Jayme 2001), as travestis se reconhecem como homens, por isso muitas delas se referem à sua orientação sexual como sendo "homossexual".

4 É importante frisar que algumas classificações não são excludentes, podendo uma "top" ser "européia", ou um "travecão" já ter sido "top", assim como uma "t-gata" pode ser "ninfetinha" ou "top". Além disso, ser "top" ou "européia" não restringe a forma de trabalho. Como diz a "top" Victória Ribeiro, se as coisas não vão bem via internet ou celular ela vai para a rua, vai "fazer pista", como dizem algumas.

5 Os blogs e fotoblogs são plataformas de sociabilidade virtual que funcionam como murais de notícias. Se diferenciam das webpages por permitirem que os visitantes da página digitem comentários sobre temas ali discutidos e, sobretudo nos fotoblogs, sobre as fotos e/ou pessoas e/ou eventos que as mesmas retratam.

6 Depoimento prestado via MSN.

7 O termo deriva da expressão "dar close".

8 Pessoa, geralmente uma travesti, que faz aplicações de silicone líquido no corpo de outras travestis ou de mulheres que buscam formas mais volumosas e arredondadas.

9 Entrevista concedida à pesquisadora, em 03/09/2005, na casa de Verônica, em São Carlos (SP).

10 O projeto preventivo em HIV/Aids Tudo de Bom!, alocado na agência pública de saúde DST/Aids Cidade de São Paulo, da Secretaria Municipal de Saúde. O mesmo é voltado para trabalhadores do sexo que atuam na capital paulistana, valendo-se da "educação entre pares" como recurso metodológico de intervenção. Desta forma, profissionais de saúde ligados ao projeto "identificam nas regiões dos seus serviços pessoas que comercializam sexo, com perfil para o trabalho em campo. Estas pessoas, após formação específica, desenvolvem intervenções em áreas de prostituição da cidade'" (Abate 2003: 33).

11 Informações divulgadas no livreto Silicone - Redução de Danos, publicado pela Associação de Travestis "Unidas na Luta pela Cidadania".

12 Queiroz (1993) aponta, em seu estudo sobre representações de cura entre pescadores, que a classificação entre alimentos quentes e frios teria, na lógica subjacente ao pensamento popular, uma correspondência com os órgãos do corpo humano. “Existiria uma correspondência entre cada órgão do corpo, caracterizado como 'frio' ou 'quente', e a susceptibilidade de uma ação dos elementos similares sobre os mesmos, por meio dos quais a doença era identificada e o tratamento elaborado" (Cardoso 1999:139).

13 Entrevista concedida à pesquisadora, em 01/05/2004, na casa da mãe de Jennifer.

14 Depoimento colhido em reunião de supervisão técnica do Projeto Tudo de Bom! (ver nota 10) em 19/04/05, nas dependências do Serviço de Assistência Especializada do Butantã (São Paulo).

15 Queiroz (1993), Cardoso (1999), Kreutz et al. (2003). Ver nota 12.

16 Forma de se referir ao tamanho do pênis.

17 Sabino vale-se desse conceito num paralelo com Dumont ao referir-se à noção de indivíduo na cultura ocidental moderna como um valor referencial. Para maior aprofundamento ver Dumont (1983) e Sabino (2004). 


\section{REFERÊNCIAS BIBLIOGRÁFICAS}

ABATE, Maria Cristina. 2003. “No Lugar da Tutela, o Diálogo e o Protagonismo”. In F. Mesquita e C. R. de Souza, DST/Aids a Nova Cara da Luta Contra a Epidemia na Cidade de São Paulo. São Paulo: Raiz da Terra.

BUTLER, Judith. 2002. Cuerpos que Importan. Barcelona: Pardos. . 2003. Problemas de Gênero: feminismo e subversão da identidade. Rio de Janeiro: Civilização Brasileira.

BENEDETTI, Marcos R. 2000. Toda Feita - O corpo e o gênero das travestis. Dissertação de mestrado. Porto Alegre: Programa de Pós-Graduação em Antropologia Social da Universidade Federal do Rio Grande do Sul.

CARDOSO, M. 1999. Médicos e Clientela - da assistência psiquiátrica à comunidade. São Carlos (SP): Fapesp/Editora UFSCar.

DENIZART, Hugo. 1997. Engenharia Erótica - Travestis no Rio de Janeiro. Rio de Janeiro: Jorge Zahar Editor.

DUARTE, Luiz Fernando Dias. 1988. Da Vida Nervosa nas Classes Trabalhadoras Urbanas. $2^{\mathrm{a}}$ ed. Rio de Janeiro: Jorge Zahar Editor/CNPq.

. 1994. "A Outra Saúde: mental, psicossocial, físico-moral?". In P. C. Alves e M. C. S. Minayo (orgs.) Saúde e Doença - um olhar Antropológico. Rio de Janeiro: Editora Fiocruz.

. 2004. "A Sexualidade nas Ciências Sociais: leitura crítica das convenções". In A. Piscitelli, M.F. Gregori e S. Carrara (orgs.) Sexualidade e Saberes: convenções e fronteiras. Rio de Janeiro: Garamond.

DUMONT, Louis. 1983. O Individualismo. Rio de Janeiro: Rocco.

FOUCAULT, Michel. 1972. “Nascimento da Medicina Social”. In Microfísica do Poder. Rio de Janeiro: Graal. . 2003. História da Sexualidade, vol. 1 - A Vontade de Saber. São Paulo: Graal.

JAYME, Juliana G. 2001. Travestis, Transformistas, Drag-queens, Transsexuais: personagens e máscaras no cotidiano de Belo Horizonte e Lisboa. Tese de Doutorado. Campinas (SP): Universidade Estadual de Campinas, Instituto de Filosofia e Ciências Humanas, Departamento de Antropologia.

KREUTZ, Irene; Miriam Aparecida Barbosa Merighi e Dulce Maria Rosa Gualda. 2003. “Cuidado Popular con Heridas: representaciones y prácticas en la comunidad de São Gonçalo, Mato Grosso, Brasil". Ciencia y Enfermería 9(1):39-53 [online, acesso em 16/09/2005], Disponível em <http://www.scielo.cl/scielo.php?script=sci_arttext\&pid=S0717-95532 003000100006 \&lng $=$ es\&nrm $=$ iso $>$

KULICK, Don. 1998. Travesti: sex, gender and culture among brazilian transgendered prostitutes. Chicago: The University of Chicago Press.

LE BRETON, David. 2003. "A Síndrome de Frankenstein". In Denise B. Sant'Anna (org.) Políticas do Corpo. São Paulo: Estação Liberdade.

LEVIGARD, Yvone Elsa. 2001. A interpretação dos profissionais de saúde acerca das queixas do nervoso no meio rural: uma aproximação ao problema das intoxicações por agrotóxicos. Dissertação de Mestrado. Rio de Janeiro: Fundação Oswaldo Cruz, Escola Nacional de Saúde Pública.

LOPES, Suzana Helena S. 1995. “Corpo, Metamorfose e Identidades - de Alan a Elisa Star”. In Ondina F. Leal (org.) Corpo 
OLIVEIRA, Neusa Maria. 1994. Damas de Paus - O jogo aberto dos travestis no espelho da mulher. Salvador: Centro Editorial e Didático.

OLIVEIRA, Marcelo J. 1997. O Lugar do Travesti em Desterro. Dissertação de Mestrado. Florianópolis: Universidade Federal de Santa Catarina, Centro Filosofia e Ciências Humanas.

PELÚCIO, Larissa M. 2004. "Travestis, a (re)construção do feminino: gênero, corpo e sexualidade em um espaço ambíguo". Anthropológicas 15(1):123-154. Recife: UFPE, Programa de Pós-Graduação em Antropologia.

QUEIROZ, Marcos S. 1993. “Estratégias de Consumo em Saúde entre Famílias Trabalhadoras". Cadernos de Saúde Pública 9(3):272-82 [online, acesso em 18/09/2005]. Disponível em <http://www.scielo.br/scielo.php?script=sci_arttext\&pid=S0102$311 \times 1993000300015$ \&lng $=$ en\&nrm $=$ iso $>$.

SABINO, César. 2004. O Peso da Forma - cotidiano e uso de drogas entre fisiculturistas. Tese de Doutorado em Sociologia. Rio de Janeiro: UFRJ, Instituto de Filosofia e Ciências Sociais, Programa de Pós-Graduação em Antropologia e Sociologia. Disponível em <http://sociologia.com.br/divu/colab/d20-csabino.pdf >.

SILVA, Hélio R. 1993. Travesti - a invenção do feminino. Rio de Janeiro: Relume-Dumará/ ISER.

SILVA, H. R. S., \& C. de O. Florentino. 1996. "A sociedade dos travestis: espelhos, papéis e interpretações. In R. Parker \& R. M. Barbosa (orgs.) Sexualidades Brasileiras. Rio de Janeiro: Relume-Dumará; ABIA; IMS/UERJ.

VIVEIROS de CASTRO, Eduardo. 1979. "A fabricação do corpo na sociedade xinguana". Boletim do Museu Nacional no 32. 
“Toda Quebrada na Plástica" - Corporalidade e construção de gênero entre travestis paulistas

\section{RESUMO}

Desde a comercialização dos hormônios femininos, na forma de contraceptivos, a construção da pessoa travesti ganhou um novo impulso. Na busca de um "corpo perfeito", isto é, associado a padrões socialmente sancionados como femininos, compôs-se todo um circuito estético e de cuidados de si que burla a medicina ocidental, por um lado, mas que em alguns momentos a ela se associa. Do modelo "travecão" ao "menininha", as travestis se submetem a inúmeros processos de intervenção corporal que se iniciam com a ingestão de hormônios, passando pela aplicação de silicone industrial até operações de redução da testa, extirpação do pomo-de-adão e renovadas sessões com "bombadeiras", pessoas que "fazem o corpo", isto é, injetam silicone nas travestis. Orientadas pela heteronormatividade compulsória, as travestis transformam seus corpos a fim de adequá-los a seus desejos, práticas e orientação sexual, reconhecidas por elas como "homossexuais". Nessa construção subvertem o gênero e paradoxalmente, também enfatizam o caráter de assujeitamento por detrás do culto contemporâneo a padrões de normalidade, saúde e beleza.

PALAVRAS-CHAVE: travestis - corporalidade - sexualidade - gênero - heteronormatividade

\section{"Complete Makeover" - Corporality and gender construction among Brazilian transvestites}

\section{ABSTRACT}

Since the commercialization of feminine hormones in the form of contraceptives, the construction of the transvestite's person has gained a new boost. In search for a "perfect body", associated with patterns socially sanctioned as feminine, an entire aesthetic circuit has developed, one that defrauds Western medicine, on the one side, but on the other associates with it. From the "travecão" model to the "little girl" one, the transvestites undergo countless processes of corporal intervention that begin with hormones ingestion, going through the application of industrial silicon in their bodies and even through surgeries to reduce the forehead, extirpation of the Adam's apple and successive sessions with the so called "bombadeiras" (pampers), people that "make the body", that is, inject silicon in the transvestites. Guided by compulsory heteronormativity, the transvestites transform their bodies in order to adapt them to their desires, practices and sexual orientation, recognized by them as "homosexuals". In this construction they subvert gender, and paradoxically, also emphasize the subjected pattern behind the contemporary cult to normality patterns, health and beauty.

KEY WORDS: transvestites - corporality - sexuality - gender - heteronormativity 